\title{
Deformation Characteristics of Cultured Single Viable Cells by Squeezing Tests
}

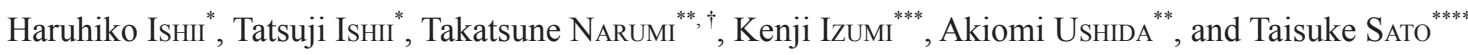 \\ "Graduate School of Science and Technology, Niigata University \\ ${ }^{* *}$ Faculty of Engineering, Niigata University \\ ${ }^{* * *}$ Niigata University Graduate School of Medical and Dental Sciences \\ ${ }^{* * * *}$ Institute for Research Promotion, Niigata University, Niigata University \\ 8050, Ikarashi 2-no-cho, Nishi-ku, Niigata, 950-2181, Japan \\ (Received : March 6, 2018)
}

\begin{abstract}
Mechanical/rheological properties of single viable cells were investigated by squeezing tests. Human oral keratinocytes were harvested from oral mucosa tissue sample, grown in a culture medium with two different calcium ion concentrations. The cells were squeezed between a convex lens and a flat plate until reaching the crushed state. The extension ratio, determined by the diameter at destruction relative to the initial diameter, was evaluated, and cell destruction patterns were classified. The extension of cells was reduced when they were cultured in the culture medium with a higher calcium ion concentration. The cell destruction patterns observed were classified into two types corresponding to the membrane rupture style. Our results indicated that cells cultured with a higher calcium ion concentration typically show a destruction pattern characterized by cell surface rupture at several parts. Moreover, the incidence ratio of the destruction patterns was highly correlated with the extension ratio of the cells.
\end{abstract}

Key Words: Single cell / Oral keratinocytes / Extensibility / Destruction property / Calcium ion concentration

\section{INTRODUCTION}

Rheological properties of living cells have been investigated to clarify cell functions in the fields of tissue engineering and cell dynamics ${ }^{1-6)}$. Deformability is one of the important properties used to characterize cells. For example, the destruction limit of the cell is useful information for cell handling processes. Previous studies demonstrated that the cell growth of epidermal keratinocytes was affected by the plasma membrane viscosity modulated with specific fatty acid supplementation, indicating the deformability of cells can be used for analyzing proliferative potential ${ }^{7-99}$.

In the last two decades, an autologous tissue-engineered oral mucosa has been applied for intraoral/extraoral grafting to treat open wounds ${ }^{10-12}$. The cultured oral keratinocytes within the grafts produce a large number of growth factors that facilitate the cellular activity of neighboring cells as well as promote wound healing as paracrine effect. In addition, cultured cells with high proliferative potential secrete a large amount of growth factors ${ }^{13-15)}$. Therefore, to predict the efficiency of the tissue-engineered oral mucosa after grafting,

\footnotetext{
$\dagger$ Corresponding author.

E-mail : narumi@eng.niigata-u.ac.jp

Tel \& Fax: +81-25-262-7014;
}

researchers need to develop a new tool to examine the quality of cells prior to grafting. Several methods are conventionally used to investigate the proliferative capacity and biological activity of cells using chemical reactions ${ }^{16-18)}$. We hypothesized the mechanical/rheological properties of cells, including physical strength, can be another approach to evaluate proliferative capacity of cells. To examine the correlation between the mechanical/rheological and proliferative capacity, cells were cultured in the culture medium containing a higher calcium concentration (1.2 $\mathrm{mM}$ or higher) that induces differentiation with losing proliferative capacity, compared with cells grown in the medium containing a lower calcium concentration. This cell culture environment will allow us to determine the degree of proliferative potential in cells.

The mechanical/rheological properties of cells have been analyzed by utilizing a variety of methods that are mainly classified into two types. One is local mechanical/rheological properties, and the other is the properties of whole cells. To measure the local ones, for example, micro-rheological properties are estimated by atomic force microscopy, laser optical tweezers, or numerical calculations ${ }^{1-3)}$. Since the results obtained are mainly concerned with micro-deformations, it seems to be difficult to determine their 
correspondence with the proliferative capacity of cells. In contrast, the deformation of the whole living tissues has also been examined, but few studies have focused on the mechan$\mathrm{ical} /$ rheological properties of living single cells in culture ${ }^{4-6)}$.

Therefore, in this study, we aimed to evaluate the deformation characteristics of single cells by a squeezing test, and then to determine the correlation between the mechanical/ rheological properties and the proliferative potential of cells, which was modulated by two different calcium ion concentrations. Our technique will eventually provide a new physical approach to evaluate biological activity of cells that should contribute to quality control in regenerative medicine.

\section{CELLS TESTED}

After the informed consent form was obtained, oral mucosa tissue samples were harvested from patients receiving a minor dent/alveolar surgery at the outpatient clinic of oral and maxillofacial surgery in our university hospital (IRB approval number of 2015-2018). The oral mucosa samples were soaked in a $0.04 \%$ trypsin solution overnight, and then oral keratinocytes were dissociated. The majority of the cells are squamous in vivo but become spherical in the cell culture environment. They were grown in a basic serum-free culture medium, EpiLife ${ }^{\circledR}$ supplemented with growth factors as well as $0.06 \mathrm{mM} \mathrm{Ca}^{2+}$, at $37^{\circ} \mathrm{C}$ in a humidified atmosphere containing $5 \% \mathrm{CO}_{2}$ for 3 days. When cells reached at 70-80\% confluency, they were collected by using $0.025 \%$ trypsin/ EDTA solution. By using trypan blue solution to discriminate viable and non-viable cells, the number of cells harvested was counted. The single cells were spherical with diameters of $20-50 \mu \mathrm{m}$ in the cell suspension. The volume fraction of the cells in the medium was approximately $1.4 \%$ when the average diameter of the cells was approximated to $30 \mu \mathrm{m}$, adjusted by the number of dispersed cells in the medium. Figure 1 shows the viable cells (non-stained) and non-viable cells (stained with blue). Moreover, mixing with the trypan blue solution was useful to confirm the outflow of cytosol from collapsed cells.

Table I shows the culture environment of cells to be tested in this study. Cells obtained from 12 individuals, referred to as $\mathrm{A}$ to $\mathrm{L}$, were examined. The tests were conducted with the cells at passages 4, 5, 6, 7 and 8 for A and only at passage 6 for the other B to L. To modulate cell proliferation, $\mathrm{Ca}^{2+}$ ion was added into the culture medium with three different concentrations: $0.06 \mathrm{mM}$ (Low $\mathrm{Ca}$; regular concentration), $1.2 \mathrm{mM}$ (High $\mathrm{Ca}$ ), and $1.8 \mathrm{mM}$ (Very High Ca: sample L only). As the calcium ion concentrations in the culture

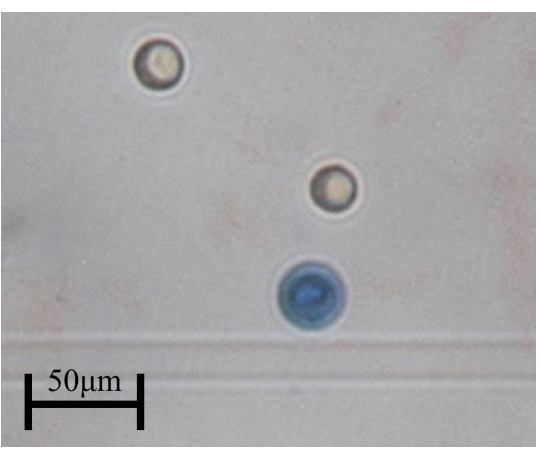

Fig. 1 Microscopic images of cells. Non-viable cells are stained with blue dye but viable cells are not.

Table I Culture environment of cells for testing.

\begin{tabular}{|c|c|c|c|c|}
\hline Subjects & A & B-K & L & Z \\
\hline Cell types & \multicolumn{3}{|c|}{ Primary culture } & Immortal \\
\hline Passage & 4-8th & 6th \\
\hline $\mathrm{Ca}^{2+}$ & \multicolumn{2}{|c|}{ Low } & $\begin{array}{c}\text { Low } \\
\text { High } \\
\text { Concentration }\end{array}$ & $\begin{array}{c}\text { Low } \\
\text { High }\end{array}$ \\
\hline
\end{tabular}

medium increase, proliferative potential of cells decreases. Moreover, immortal epithelial cells (referred to as $\mathrm{Z}$ ) having a very high proliferative ability were also tested.

\section{EXPERIMENT}

Figure 2 shows a diagram of the experimental apparatus. Cells in a phosphate-buffered saline on a flat glass plate were squeezed by a convex lens $(52 \mathrm{~mm}$ in radius of curvature) mounted on a mechanical stage. Due to the curvature of the convex lens, the gap between the lens surface and the plate increases from the center of the lens (nearest point). The gap where the cell is located is estimated by the following method. Since the curvature of the lens is relatively greater than the distance of the cell from the center, the curved surface of the lens is approximated by a quadratic curve. The gap was estimated according to the following equation: $h=$ $9.78 w^{2}+h_{0}$ (unit : m), where $w$ is the position of the cell and $h_{0}$ is the center gap. However, the gradient of the lens at the cell is negligible compared with the cell size, and cell deformation is considered to occur by squeezing between two parallel plates.

The gap between the plate and the lens at the center $\left(h_{0}\right)$ was narrowed from $50 \mu \mathrm{m}$ to $3 \mu \mathrm{m}$ at a rate of $10 \mu \mathrm{m} / \mathrm{s}$. The convex lens was moved by a pulse motor controlled mechanical stage operating at a resolution of 1 pulse $=1 \mu \mathrm{m}$. Figure 3 shows three calibrated curves of the squeezing tests in which the lens moved from $50 \mu \mathrm{m}$ to $3 \mu \mathrm{m}$ and then back to a 10- $\mu \mathrm{m}$ gap. The position of the lens was measured using a laser displacement gage. Figure 3 indicates the smooth 


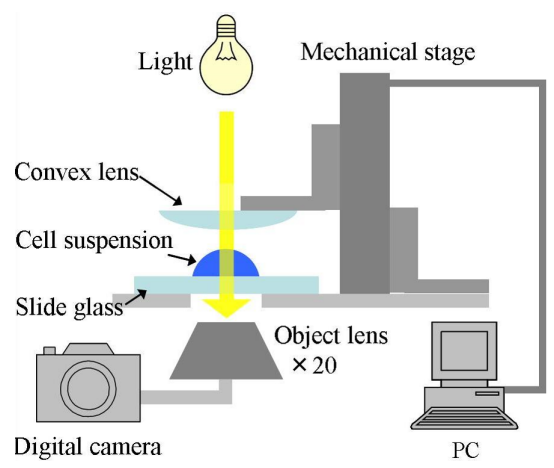

Fig. 2 Diagram of experimental apparatus.

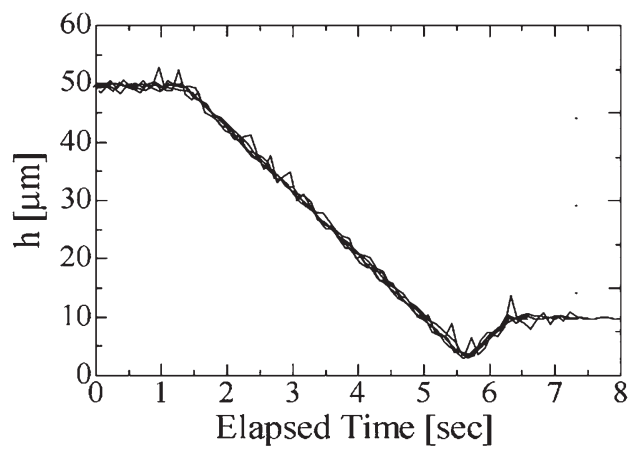

Fig. 3 Calibration of the gap $(h)$ between a convex lens and a grass plate controlled with a pulse stage.

motions of the lens and repeatability of the tests. The deformation processes of the cells were captured using a digital camera and a microscope through a $20 \times$ objective lens. The cell diameter was measured using image processing software Image-Pro Plus.

\section{RESULTS AND DISCUSSION}

\subsection{Measurement of cell diameter}

Figure 4 shows typical images of a squeezed cell. In Fig. 4 (c), $h=6 \mu \mathrm{m}$ corresponds to the collapsed state by the gap narrowing. In this experiment, it was well-recognized to define the moment of collapse, that is, when the cell membrane was ruptured, based on the outflow of cytosol from the cell. The apparent diameter of the squeezed cell was measured from the images. Because the shape of the cell was very close to a circle, as shown in Fig. 5, the diameter of cells was calculated using image processing software. The cell size was determined by an average of the diameter measured in triplicate for each cell image.

\subsection{Deformation process of cells}

To confirm the deformation of the cell shape, the experimentally obtained cell diameters were compared with predicted values. In the prediction, the shape of the cell before deformation was assumed to be a sphere of $d_{0}$ in diameter,

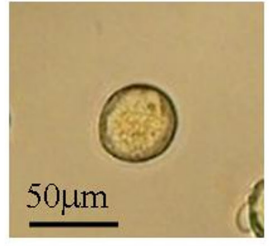

(a) $\mathrm{h}=50 \mu \mathrm{m}$

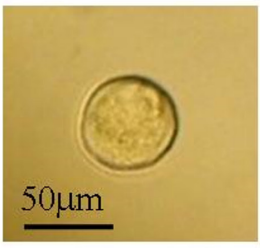

(b) $\mathrm{h}=20 \mu \mathrm{m}$

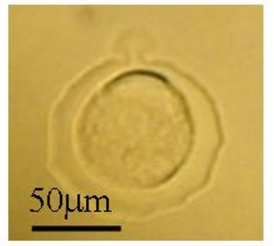

(c) $\mathrm{h}=6 \mu \mathrm{m}$
Fig. 4 Images of a cell squeezed from (a) the initial state to (c) the destruction state.

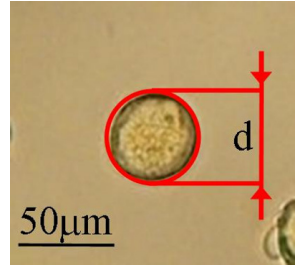

Fig. 5 Measurement of the apparent diameter of a cell.

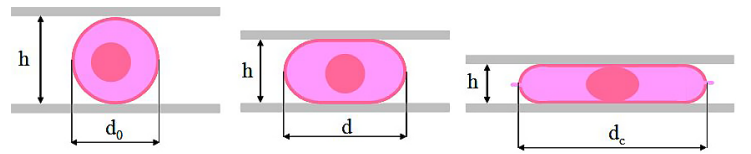

Fig. 6 Expected cell deformation.

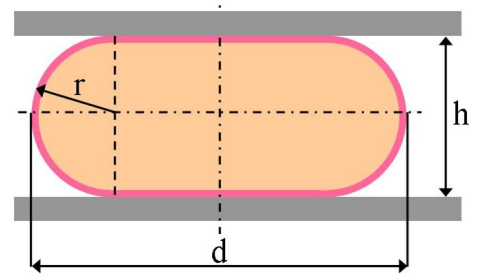

Fig. 7 Expected shape of a squeezed cell.

and the shape of flattened cells indicated in Fig. 6 was modeled according to Fig. 7. The cell has an apparent diameter $d$, thickness $h$, and semicircular shape with a circumference of the curvature of $r=h / 2$. From these assumptions, the apparent diameter was obtained by Eq. (1).

$$
d=\frac{h}{4}(4-\pi)+\sqrt{\left(\frac{\pi}{8}-\frac{1}{3}\right) h^{2}+\frac{d_{0}^{3}}{6 h}}
$$

Typical results obtained for the Low Ca condition were compared with the prediction Eq. (1) in Fig. 8. Open marks indicate the diameter measured before the collapse and solid marks indicate the break point. The prediction is indicated by a red dotted line. The squeezing process proceeds from right ( $h=d_{0}$ : black dotted line) to left in the figure. As shown in this figure, the experimental results and the predicted values showed good agreement. This indicates that the initial spherical assumption and the subsequent method for calculation were appropriate. Since similar results were obtained for different $\mathrm{Ca}$ concentration conditions, the assumptions of Eq. (1) were valid. We next focused on the extension ratio (ER), which is the ratio of the diameter $d_{c}$ at the time of collapse to the initial diameter $d_{0}$. 


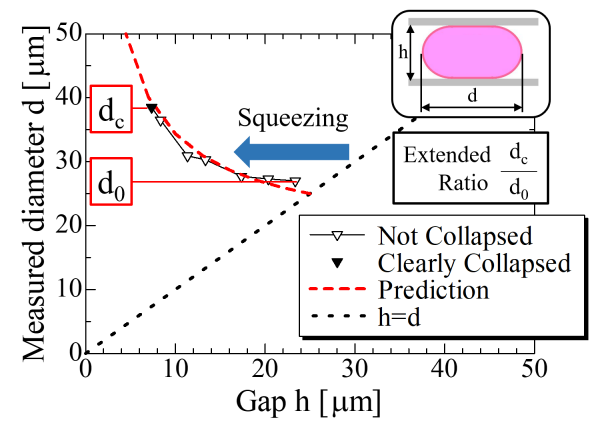

Fig. 8 Deformation processes determined by the diameter of a cell during the squeezing test.

\subsection{Effect of culture environment on cell extensi- bility}

Figure 9 shows the dependence of the extension ratio on the number of passages using cells from subject A. The cells were grown in an EpiLife culture medium with low and high calcium ion concentrations and evaluated at passage numbers 4 to 8 . Since we obtained very scattered data for 30 to 40 measurements in the respective conditions, statistical differences between two $\mathrm{Ca}$ concentrations were evaluated by $t$-tests. Superscript asterisks $(*)$ on the passage number in the figure show significant differences between low and high $\mathrm{Ca}$ concentrations. We detected the maximum ER at passage numbers 5 to 6 for both concentrations. This finding may indicate that excessive passages induce the degradation of mechanical properties. Additionally, the ER obtained from High Ca was smaller than that of Low Ca from passages 4 to 7. A similar trend was obtained from other cells derived from different individuals. According to these results, the proliferative capacity of cells controlled by a $\mathrm{Ca}$ ion concentration appeared to affect the mechanical properties of cells. So, we will make comparisons among different individuals utilizing results at the identical passage number of 6 .

Next, the same examinations were performed using cells from 13 different individuals ( $\mathrm{A}$ to $\mathrm{L}, \mathrm{Z}$ ) at the identical passage number of 6. As shown in Fig. 10, although there were large differences of the ER among individuals, the ER of cells cultured in a high $\mathrm{Ca}$ medium was smaller than that in a low $\mathrm{Ca}$ medium, which was significantly different. We also found that the ER of cells grown in a Very High Ca medium showed the lowest, compared with that of Low and High Ca media. In contrast, the ER of Z (immortal cells) exhibited large variations, resulting in no statistical differences between the two Ca concentrations although a similar tendency was observed between them. Moreover, it was noted that the average $\mathrm{ER}$ of $\mathrm{Z}$ in two $\mathrm{Ca}$ concentrations tested was greater than that of cells from other individuals. In

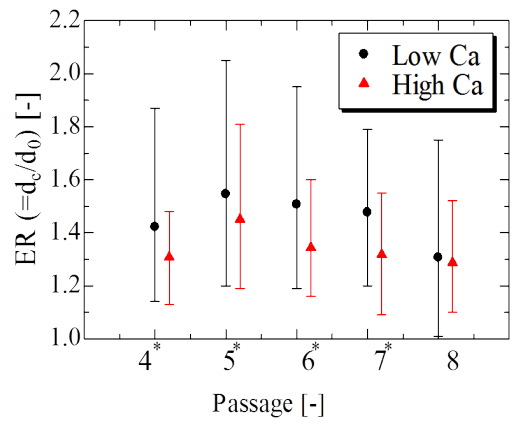

Fig. 9 Dependence of the extension ratio on passage number for cells from A. * indicates a significant difference between Low $\mathrm{Ca}$ and High $\mathrm{Ca}$ concentrations for the passage number indicated.

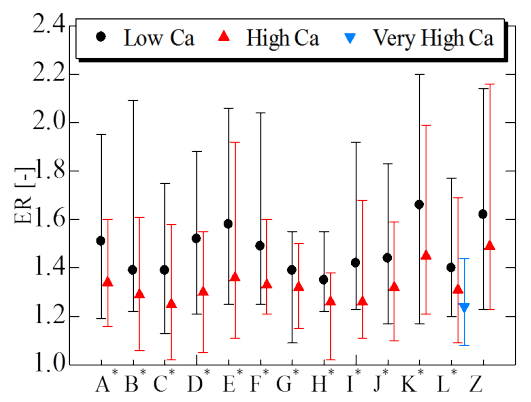

Fig. 10 Extension ratio of cells at passage 6 obtained from 13 different individuals.

conclusion, this study revealed that the mechanical strength of cells diminished when cultured in the medium with a high $\mathrm{Ca}$ concentration, which eventually causes loss of proliferative potential.

\subsection{Cell destruction patterns}

We also scrutinized the process of cell collapse, and found that the cell destruction patterns observed in this study could be classified into two types, namely, Type I and II. Figure 11 shows the typical progression of cell collapse. As shown in Fig. 11 (a), in the case of Type I, the cell membrane ruptures at a single location (upper side, in this case) and the cytoplasm flows out from this region. In the case of Type II, as shown in Fig. 11 (b), the cell surface is ruptured at several portions. Both destruction patterns occurred even in cells from the same individual and the same Ca concentration. We calculated the incidence ratio of Type I destruction.

The relationship between the incidence ratio of the Type I destruction pattern and the mean $\mathrm{ER}$ value for different $\mathrm{Ca}$ concentrations and individuals are summarized in Fig. 12. The abscissa indicates the ratio of Type I, and the ordinate indicates the average ER value. We observed positive correlations between the ER and the ratio of Type I collapse. The individual differences in ER may be denoted by the ratio of collapse patterns, that is, the cell membrane property such as flexibility. It should be noted that since we estimated the ER from 30-40 samples in each condition, a rate of $5 \%$ Type I 
(a) Type I (ruptured at one place)
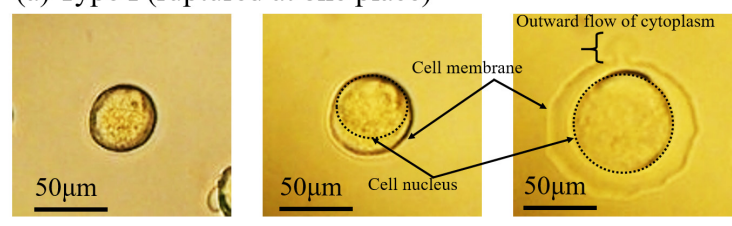

(b) Type II (ruptured at several place)
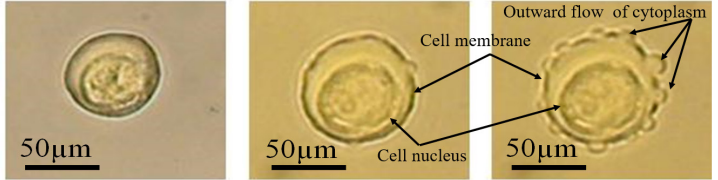

Fig. 11 Typical collapsing procedures of the cells. (a) Type I, cell membrane is ruptured from one place (original figure at Fig. 4); (b) Type II, cell surface is ruptured at several portions.

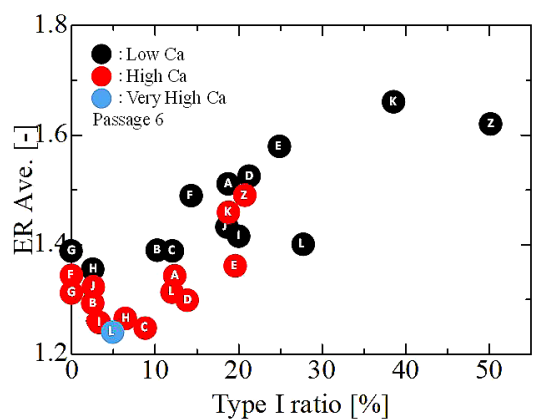

Fig. 12 Relationship between incidence ratio of Type I destruction pattern and mean value of ER for each calcium concentrations and individuals (A to L, Z).

means that only 1 or 2 cells showed Type I destruction among all samples. Therefore, it is difficult to determine differences in membrane properties from the cases with Type I ratios of $5 \%$ or less. However, we observed six cases (F, I, J, K, L, and $\mathrm{Z}$ ) with greater than $10 \%$ differences in the Type I ratio between Low and High Ca concentrations. Moreover, for most of the individuals, the ratio of Type I collapse of cells grown in a High Ca medium smaller than that of cells in a Low $\mathrm{Ca}$ medium. Based on these results, we can conclude that cells grown in a High $\mathrm{Ca}$ medium decrease the flexibility of the cell membrane, leading to decrease in ER (extensibility). In other words, the Type I ratio could also be one of the useful factor to estimate the degree of proliferative potential in cells.

Additional research is necessary to determine the cell membrane properties. In general, it is considered that the cytoskeleton contributes to the mechanical properties of cells. In some cells (such as fibroblasts), mechanical strength is thought to be mainly affected by actin filaments. Few studies have examined the mechanical properties of epithelial cells. Lulevich et al. have found that keratin intermediate filaments are the most important factor to regulate the mechanical properties of cell membrane ${ }^{6}$. In the present study, calcium ions in the culture medium could affect the cytoskeleton underneath the cell membrane, and a change in intermediate filaments could affect membrane flexibility.

\section{CONCLUSION}

Mechanical properties of single viable cells harvested from different individuals were examined by squeezing tests to assess cell destruction characteristics. Moreover, the extension property of cells decreased when they were cultured in the culture medium with a higher calcium ion concentration. In addition, our results suggested that the mechanical properties of the cell membrane were diminished with an increase in a calcium concentration, which induces differentiation as well as loss of proliferative potential of oral keratinocytes. These effects can be recognized based on the rupture of the cells. In particular, the cell destruction patterns observed in this study can be classified into two types (Type I and II) corresponding to the membrane rupture mode. We also found that the incidence ratio of Type I, in which the cell membrane is ruptured from a single location, was positively correlated with the ER at the time of cell collapse. Therefore, the measurement of mechanical/rheological properties of oral keratinocytes could be another tool to determine the cellular proliferative potential although further studies are necessary.

\section{ACKNOWLEDGEMENT}

The authors gratefully acknowledge the help of Mr. Ryuichi Kayaba in making the experimental apparatus, and Dr. Hiroko Kato and Dr. Aki Shiomi in the preparation of cells.

\section{REFFERENCES}

1) Takahashi R, Okajima T, Applied Physics Letters, 107, 173702 (2015).

2) Mizuno D, Bacabac R, Tardin C, Head D, Schmidt CF, Physical Review Letters, 102, 168102 (2009).

3) Caille N, Thoumine O, Tardy Y, Meister JJ, Journal of Biomechanics, 35, 177 (2002).

4) Dao M, Lim CT, Suresh S, Journal of the Mechanics and Physics of Solids, 51, 2259 (2003).

5) Yokokura T, Nakashima Y, Yonemoto Y, Hikichi Y, Nakanishi Y, International Journal of Engineering Science, 114, 41 (2017).

6) Lulevich V, Yang HY, Isseroff RR, Liu GY, Ultramicroscopy, 110, 1435 (2010).

7) Marcelo CL, Duell EA, Rhodes LM, Dunham WR, Journal of Investigative Dermatology, 99, 703 (1992).

8) Marcelo CL, Rhodes LM, Dunham WR, Journal of Investigative Dermatology, 103, 564 (1994).

9) Marcelo CL, Dunham WR, Journal of Investigative Dermatology, 108, 758 (1997).

10) Izumi $\mathrm{K}$, Feinberg $\mathrm{SE}$, Terashi $\mathrm{H}$, Marcelo $\mathrm{CL}$, Tissue 
Engineering, 9, 163 (2003).

11) Izumi K, Terashi H, Marcelo CL, Feinberg SE, Journal of Dental Research, 79, 798 (2013).

12) Iida $T$, Takami Y, Yamaguchi R, Shimazaki S, Harii K, Scandinavian Journal of Plastic and Reconstructive Surgery and Hand Surgery, 39, 138 (2005).

13) Kuo S, Zhou Y, Kim HM, Kato H, Kim RY, Bayar GR, Marcelo CL, Kennedy RT, Feinberg SE, Journal of Dental Research, 94, 78 (2015).

14) Nakanishi Y, Izumi K, Yoshizawa M, Saito C, Kawano Y, Maeda T, International Journal of Oral and Maxillofacial Surgery, 36, 928 (2007).
15) Mosmann T, Journal of Immunological Methods, 65, 55 (1983).

16) Ishiyama $M$, Tominaga $H$, Shiga $M$, Sasamoto $K$, Ohkura $Y$, Ueno K, Biological and Pharmceutical Bulletin, 19, 1518 (1996).

17) Tsukatani $T$, Suenaga H, Higuchi $T$, Akao $T$, Ishiyama $M$, Ezoe K, Matsumoto K, Journal of Microbiological Methods, 75, 109 (2008).

18) Kim NW, Piatyszek MA, Prowsw KR, Harley CB, West MD, Ho PLC, Coviello GM, Wright WE, Weinrich SL, Shay JW, Science, 266, 2011 (1994). 